\title{
Flexibility Transformation Decision-Making Evaluation of Coal-Fired Thermal Power Units Deep Peak Shaving in China
}

\author{
Jianjun Wang ${ }^{1,2, *}$, Jikun Huo ${ }^{1}$, Shuo Zhang ${ }^{1}$, Yun Teng ${ }^{1}$, Li Li $^{3}$ and Taoya Han ${ }^{1}$ \\ 1 School of Economics and Management, North China Electric Power University, Beijing 102206, China; \\ hjkwork2019@163.com (J.H.); 15210159862@163.com (S.Z.); tengyungoodboy@163.com (Y.T.); \\ hanty1119@163.com (T.H.) \\ 2 Beijing Key Laboratory of New Energy and Low-Carbon Development, North China Electric Power \\ University, Beijing 102206, China \\ 3 School of Economics and Management, Beijing Information Science \& Technology University, Haidian district, \\ Beijing 100192, China; lilinw2001@126.com \\ * Correspondence: wangjianjun@ncepu.edu.cn
}

Citation: Wang, J.; Huo, J.; Zhang, S.; Teng, Y.; Li, L.; Han, T. Flexibility Transformation Decision-Making Evaluation of Coal-Fired Thermal Power Units Deep Peak Shaving in China. Sustainability 2021, 13, 1882. https://doi.org/10.3390/su13041882

Academic Editor: Semih Eser

Received: 13 December 2020

Accepted: 4 February 2021

Published: 9 February 2021

Publisher's Note: MDPI stays neutral with regard to jurisdictional claims in published maps and institutional affiliations.

Copyright: (c) 2021 by the authors. Licensee MDPI, Basel, Switzerland. This article is an open access article distributed under the terms and conditions of the Creative Commons Attribution (CC BY) license (https:// creativecommons.org/licenses/by/ $4.0 /)$.

\begin{abstract}
According to China's economic green ecological sustainability development requirement, the energy reform of China is mainly increasing the proportion of renewable energy, and reducing the proportion of fossil energy. It will continue to force China's thermal power units, especially coal-fired thermal power units, to carry out the flexibility transformation and upgrading of deep peak shaving ability. Due to the different characteristics of coal-fired thermal power units, it is necessary to make flexible transformation decisions by a scientific and reasonable decision-making evaluation method, so as to provide references for the one machine-one policy flexibility transformation of thermal power units. In this paper, a decision-making evaluation index system for the flexibility transformation of coal-fired thermal power units under the demand of deep peak shaving is established. The index system considers the impact of deep peak shaving on the boilers, steam turbines, and auxiliary equipment of coal-fired thermal power units, as well as the effects of the peak shaving. A hybrid evaluation method combined set-valued iteration and GRA-TOPSIS is employed to obtain the weight of the indexes. Finally, an empirical research was conducted based on the index system and the hybrid evaluation method and targeted "one machine, one policy" recommendations were put forward for the flexibility transformation of the coal-fired thermal power units.
\end{abstract}

Keywords: coal-fired thermal power unit; flexibility transformation; decision-making evaluation; GRA-TOPSIS

\section{Introduction}

China's resource endowment is characterized by "rich coal, poor oil, and less gas", which determines that China's power generation structure has been dominated by coalfired power generation for a long time. The coal-fired power generation provides China with the necessary energy for economic development, but it also brings a series of environmental problems, such as air pollution. To solve the problems, China has decided to take the road of sustainable ecological economic development and carry out clean energy supply-side reforms. One of the important ways is to increase the proportion of renewable energy, optimize the energy supply structure, and coordinate the handling of energy supply and demand, economic development, and environmental issues.

The development of renewable energy power generation, such as wind power and photovoltaic power generation, is the consensus of the developed countries in the world to respond to climate change. Wind and photovoltaic power generation are developing rapidly with the related policies' encouragement and the technological progress to reduce the cost of new energy power generation. However, in this background, the ratio of the traditional coal-fired power generation should be reduced to adapt to the energy sustainable 
development requirement, meaning that the coal-fired units should be considered with deep peak shaving transformation. This refers to rapidly changing the output power of the coal-fired power plants in response to the variable residual load on different time scales, for adjusting the coal-fired output power to adopt more renewable generation power output. Summarizing the advanced experience in the new energy development in Europe, it is found that the development of wind power and photovoltaic power generation is inseparable from the support of flexible peak-shaving power sources such as thermal power [1]; Germany, as a benchmark country for the development of new energy in Europe, now has a stronger demand for the flexible thermal power than before [2]; Denmark has achieved wind power generation accounting for $42 \%$ of the total power generation in 2015, but this achievement is inseparable from the guarantee of deep peak shaving power supply from neighboring countries. From the perspective of the current situation of renewable energy utilization in Europe, it is an effective strategy to support the development of new energy by increasing the capacity of deep peak shaving of conventional thermal power units and carrying out flexibility transformation of thermal power units [3,4].

On the energy demand side, with the development of energy storage technology and multi-energy complementary power generation technology, as well as the further improvement of demand response mechanisms, the energy demand side management requires stronger power supply flexibility [5]. The energy storage technology will make the power system more flexible [6,7]. Energy storage equipment enhances the demand response capability of the power system, but it also requires the flexibility transformation of deep peak shaving for thermal power units to ensure the safe operation of the power system [8].

The flexibility transformation of the coal-fired generation units of deep peak shaving needs to pay attention to the three indexes: peak shaving capacity, ramping speed, and start-stop time [3]. The flexibility transformation of China's thermal power plant is a key way of increasing renewable energy consumption. However, due to the different ages of China's thermal power plant construction, if the overall flexibility transformation is carried out in a unified manner, it is difficult to achieve the ideal solution of the energy supply in China [9]. This requires that the flexibility transformation plan of "one machine, one policy" should be formulated according to the actual situation of the units $[10,11]$. Ye has studied the different flexible technical transformation routes for heating units and pure condensing units and pointed out that the atmospheric hot water Storage tank is usually a better transformation plan in Northeast China from the economic aspect [12]. In the analysis of the operation law of deep peak shaving of thermal power plants in Northeast China, Liu Gang analyzed the technical routes of flexibility transformation of cogeneration units and pure condensing units from the aspects of safety and economy and presented the flexibility transformation route of two units, respectively [13]. Avagianos has conducted research on three types of lignite drying technologies related to the flexibility transformation of thermal power units and put forward suggestions on the flexibility transformation scheme that should be adopted for thermal power units with the objectives of economy and carbon emission reduction, respectively [14].

With the renewable energy development in the past ten years, the installed capacity of renewable energy power generation in China has developed rapidly. In 2017, the wind turbine assembly capacity installed in China accounted for $37 \%$ of the world's total, and the photovoltaic generator assembly capacity accounted for $50 \%$ of the world's total [15]. Due to the fact that the ratio of renewable energy power generation is gradually increasing, the randomness and uncertainty of renewable energy power generation bring a big challenge for power energy supply. To ensure the energy supply sustainable development safety, it is required that the whole power system must reserve a sufficient safe operation margin, including backup power capacity, energy storage capacity, and power transmission capacity [16]. According to the prediction of the Energy Research Institute of National Development and Reform Commission, the installed capacity of thermal power in China will drop to less than $50 \%$ by 2050 . The proportion of wind energy and solar energy in- 
stalled capacity will continue to increase and is expected to exceed $64 \%$ of the total installed capacity by 2050 [17]. In the future, the overall strategy for the optimization of power generation structure in China will be to increase the proportion of renewable energy power generation, gradually reduce the proportion of coal-fired thermal power generation, and carry out peak shaving flexibility transformation for coal-fired thermal power plants [18]. Therefore, to vigorously develop new energy power generation, it is necessary to gradually strengthen the peak shaving capacity of thermal power generation, so that thermal power, especially coal-fired units, becomes the main force for deep peak shaving and frequency modulation of the power grid.

Compared with developed countries, the main problem of power supply development in China at this stage is that the coal-fired generation's scale is surplus and the flexibility is insufficient. Ensuring the safety and stability of thermal power units during low-load operation is an important foundation for thermal power to play its role in peak shaving. With the gradual deepening of the reform on both sides of energy supply and demand in China, it is an inevitable trend for thermal power units to carry out the flexibility transformation of deep peak shaving. Under the requirements of energy saving and emission reduction of China, backward coal-fired thermal power units will be further reduced [7]. With the continuous increase in renewable energy and demand-side resources, the flexible supply of the power system has also increased, which also requires the deep peak shaving transformation of conventional thermal power units [8]. It is necessary to evaluate the project for the flexibility transformation of coal-fired units in the entire thermal power industry according to the actual situation. In the entire evaluation process, it is of great significance to conduct a scientific program evaluation for the deep peak shaving project of coal-fired thermal power units during the planning period.

The level of the project planning evaluation always directly affects the final effect of the flexibility transformation of coal-fired units, and the impact of coal-fired units and the power grid during low-load operation should be considered as much as possible during the planning period. Therefore, it is necessary to make a scientific decision-making evaluation on the flexibility transformation of coal-fired units in the planning period under the demand of deep peak shaving background, so as to provide reasonable suggestions for the flexibility transformation of coal-fired units. This paper first summarizes the key characteristics and factors of the flexibility transformation of coal-fired thermal power units and establishes a decision-making evaluation index system. Since the evaluation of the flexibility transformation of coal-fired units is a pre-assessment, it is necessary to employ expert experience and relevant quantitative data for pre-judgment. This paper selects a hybrid evaluation method with a subjective weighting method based on improved set-value iteration and the comprehensive evaluation method based on GRA-TOPSIS, conducts a decision-making evaluation on flexibility transformation of coal-fired units through empirical research, and presents relevant suggestions according to the results of the evaluation study.

The rest of the paper is organized as follows: Section 2 provides the decision-making evaluation index system for flexibility transformation of the coal-fired thermal power units under deep peak shaving requirement. In Section 3, a hybrid evaluation method combined with the set-valued iterative method and the GRA-TOPSIS method are proposed for the decision-making. Section 4 provides a case study and the results analysis, and some suggestions are given to the coal-fired thermal power units. Section 5 is the conclusion of the paper.

\section{Decision-Making Evaluation Index System for Flexibility Transformation of Coal-Fired Thermal Power Units under Deep Peak Shaving}

Thermal power generation units will hold a relatively low proportion of the power supply structure in the context of deep peak shaving demand for energy sustainable development requirement in China. Therefore, coal-fired thermal power units will also decrease their proportion in the power supply structure. In the current situation of coalfired thermal power units in China, many coal-fired thermal power units need to operate 
at a lower level of power generation in the context, and the available hours and power generation capacity of the generating units will be further reduced. In the decision-making of flexibility transformation of coal-fired units, it is necessary to consider that the operating state of coal-fired thermal power units during deep peak shaving may deviate from the design condition, which may lead to operational risks. If the operational risks can be estimated during the decision-making period of the coal-fired units, the operation risk will avoid a lot after the flexibility transformation project, so as to make the decision more reasonable. This paper extensively collects the expert opinions and the current actual conditions of coal-fired units in China and organizes the indexes based on the characteristics of low-load operation of thermal power units under deep peak shaving demand. The flexibility transformation decision-making evaluation indexes of thermal power units are designed during the planning period under deep peak shaving demand is shown in Table 1.

Table 1. The decision-making evaluation index system for the flexibility transformation planning of thermal power units under deep peak shaving.

\begin{tabular}{|c|c|c|c|c|c|}
\hline Primary Indexes & Secondary & Idexes & Symbol & Index Type & Description \\
\hline \multirow{7}{*}{ Boiler side } & \multirow{4}{*}{ Stable combustion risk } & $\begin{array}{l}\text { Boiler minimum } \\
\text { combustion stable } \\
\text { load rate }\end{array}$ & R1 & Quantitative & $\begin{array}{c}\text { Calculated by boiler maximum continuous } \\
\text { rating (BMCR), unit: } \%\end{array}$ \\
\hline & & Coal quality & $\mathrm{R} 2$ & Quantitative & $\begin{array}{c}\text { Ash, moisture, volatile matter, low calorific } \\
\text { value }\end{array}$ \\
\hline & & $\begin{array}{l}\text { Working condition } \\
\text { of coal feeding } \\
\text { system }\end{array}$ & $\mathrm{R} 3$ & Qualitative & $\begin{array}{l}\text { Coal quality, load followability (accurate } \\
\text { measurement and flexible adjustment), } \\
\text { coal leakage }\end{array}$ \\
\hline & & $\begin{array}{c}\text { Burner } \\
\text { characteristics }\end{array}$ & $\mathrm{R} 4$ & Qualitative & $\begin{array}{l}\text { Mainly related to the combustion method } \\
\text { (coal combustion, fluidized bed boiler, etc.) }\end{array}$ \\
\hline & Steam temperature & aracteristic risk & R5 & Quantitative & $\begin{array}{l}\text { Relationship between superheater or } \\
\text { reheater outlet steam temperature and } \\
\text { boiler load }\end{array}$ \\
\hline & Hydrodynami & ystem risk & R6 & Qualitative & $\begin{array}{l}\text { Heat transfer deterioration, local over } \\
\text { temperature, stagnant water circulation or } \\
\text { backflow, etc. }\end{array}$ \\
\hline & Excessive en & sion risk & R7 & Quantitative & $\begin{array}{l}\text { Dust removal, denitration, and } \\
\text { desulfurization }\end{array}$ \\
\hline \multirow{3}{*}{ Steam turbine side } & Steam turbir & unit risk & R8 & Qualitative & Generation efficiency, unit life \\
\hline & Last bla & risk & R9 & Qualitative & Water erosion, tremor, etc. \\
\hline & Steam turbine & linder risk & R10 & Qualitative & $\begin{array}{l}\text { Temperature difference, differential } \\
\text { expansion, vibration, etc. }\end{array}$ \\
\hline \multirow{2}{*}{ Auxiliary side } & Auxiliary equ & ment risk & R11 & Qualitative & $\begin{array}{l}\text { Auxiliary equipment (high and low } \\
\text { pressure heaters, etc.) deviate from design } \\
\text { conditions }\end{array}$ \\
\hline & Couplir & risk & R12 & Qualitative & $\begin{array}{l}\text { Coupling (combustion adjustment, body } \\
\text { heat storage, steam quality, etc.) }\end{array}$ \\
\hline \multirow{4}{*}{ Peak shaving effect } & Peak shaving & argin risk & R13 & Quantitative & $\begin{array}{c}\text { Related to peak shaving ability and } \\
\text { bilateral randomness }\end{array}$ \\
\hline & Control sy & $\mathrm{m}$ risk & R14 & Qualitative & $\begin{array}{l}\text { Software and hardware failures (such as } \\
\text { valve characteristics, multi-system } \\
\text { compatibility) }\end{array}$ \\
\hline & Peak shaving & ategy risk & R15 & Qualitative & $\begin{array}{l}\text { The strategies of deep peak shaving, } \\
\text { startup and shutdown, energy storage } \\
\text { participation, and joint dispatching are } \\
\text { considered }\end{array}$ \\
\hline & Flexibility trans & mation risk & R16 & Qualitative & $\begin{array}{c}\text { The transformation cost and the capacity } \\
\text { of deep peak shaving after transformation } \\
\text { are considered }\end{array}$ \\
\hline
\end{tabular}

The index system includes four primary indexes, which mainly consider the impact of deep peak shaving on coal-fired thermal power unit boilers, steam turbines, and auxiliary equipment, as well as the effect after the unit's performance after peak shaving. The corresponding secondary indexes involve 13 types of risks, of which the stable combustion risk is generally considered to be the most important risk affecting the safe and stable 
operation of coal-fired thermal power units, and its evaluation is also more complicated, so it is subdivided into 4 secondary indexes. Among the 16 secondary indexes, five indexes are quantitative indexes, and accurate evaluation values can be obtained directly through monitoring and statistical data; the remaining 11 indexes are qualitative indexes, which need to be evaluated by experts combined with relevant information and their own experience. The descriptions of 16 secondary indexes are shown in Table 1, and the evaluation methods are described below for five quantitative indexes.

\subsection{Boiler Minimum Combustion Stable Load Rate (BMLR)}

$$
B M L R=\frac{\text { Boiler minimum stable load without auxiliary fuel support }}{B M C R}
$$

The $B M L R$ can be calculated as Equation (1). The lower the BMLR value, the better the peak shaving performance of the unit. The design value of BMLR for thermal power units is generally $50-60 \%$, and for supercritical units up to $30 \%$, it can reach $20-40 \%$ after flexibility transformation [3]. Because the large ratio of renewable generation will take part in the electricity market, the lower BMLR after flexibility transformation planning will make the thermal power units better participate in the electricity market transactions, and it will make the thermal power unit much more able to cope with the uncertainty of the renewable generation output in the electricity market.

\subsection{Coal Quality}

Four factors including ash content (unit: \%), moisture content (unit: \%), volatile content (unit: \%) and low calorific value (unit: $\mathrm{MJ} / \mathrm{kg}$ ) are considered for coal quality [19]. The empirical weight value $\mathrm{w}=\{0.2,0.2,0.2,0.4\}$ is taken as the factor weight, and the Z-score standardized result of the measured value is taken as the factor evaluation value. Among them, ash, moisture, and volatile content need to be normalized first. The normalization processing formula and z-score standardization processing formula are as Equations (2) and (3):

$$
\begin{aligned}
x^{\prime} & =x_{\max }-x \\
x^{\prime} & =(x-\mu) / \delta
\end{aligned}
$$

where $x_{\max }$ represents the maximum value of the measured value $x, \mu$ is the mean value, and $\delta$ is the standard deviation. The larger the coal quality evaluation value always means better stable combustion of the thermal unit's capability, and it also can better cope with the uncertainty of the renewable generation output in the electricity market.

\subsection{Steam Temperature Characteristic Risk}

Steam temperature characteristic refers to the relationship between the outlet steam temperature (unit: ${ }^{\circ} \mathrm{C}$ ) of the superheater or reheater and the boiler load (unit: \%). Generally, the steam temperature characteristic curve can be fitted as a straight line. The more stable the steam temperature characteristic curve is, the better the peak shaving performance of the unit is, and it also means the thermal unit can much easier control its output flexible in order to cope with the uncertain environment of the electricity market. Therefore, a straight slope is considered to describe the risk of steam temperature characteristics as Equation (4).

$$
r=\left|\frac{n \sum t_{i} l_{i}-\sum t_{i} \sum l_{i}}{n \sum l_{i}^{2}-\left(\sum l_{i}\right)^{2}}\right|, i=1,2, \ldots, n
$$

where $r$ is the steam temperature characteristic risk, $n$ is the monitoring times, $t_{i}$ is the steam temperature monitored for the $i$ time, and $l_{i}$ is the load. The lower the steam temperature characteristic risk evaluation value, the better. 


\subsection{Excessive Emission Risk}

Thermal power units are generally equipped with denitrification, dust removal, and desulfurization equipment. Low-load operation of the unit will cause equipment efficiency to decrease or stop operation, even corrode or block the equipment, shorten the life of the catalyst, and cause excessive emissions. Considering the content of sulfur dioxide (unit: $\mathrm{mg} / \mathrm{m}^{3}$ ), nitrogen oxide (unit: $\mathrm{mg} / \mathrm{m} 3$ ) and particulate matter (unit: $\mathrm{mg} / \mathrm{m}^{3}$ ) in flue gas, the weight is the empirical value $\mathrm{w}=\{0.4,0.3,0.3\}$. The evaluation value takes the $\mathrm{Z}$-score standardized result of the actual measured value. The smaller risk evaluation value of excessive emission means the thermal power unit can remain a low-load operation with stable output, it will make the thermal power unit survive in the electricity market.

\subsection{Peak Shaving Margin Risk}

Peak shaving margin risk is affected by the deep peak shaving demand, which is the difference between the uncertain new energy power generation output curve and the load demand curve. The coal-fired unit performs its peak shaving capability under the constraints of maximum power and the BMLR and ramp rate [20]. In order to simplify the evaluation process and consider the feasibility of data collection, the risk of peak shaving margin is described by the total time of unit rapid ramp time (ramp rate up and down load time) plus the oil feeding operation and shutdown time (including startup and shutdown time). The lower peak shaving margin risk means the thermal unit can respond to the uncertain electricity market rapidly.

In the above index system, the main impact of low load operation on the coal-fire unit and the power grid is considered. Additionally, the other qualitative of the impact of the low-load operation of the thermal power unit's performance of the power grid indexes are considered. A high level of risk means that the deep peak shaving capability of units is poor, and it also means that the thermal power unit is much less able to cope with the uncertain renewable generation output in the electricity market, and the flexibility transformation panning of higher risk is recommended earlier.

\section{Hybrid Decision-Making Evaluation Model of Peak Shaving in Planning Period Based on Set-Valued Iteration and GRA-TOPSIS}

In the index system for the decision-making evaluation of the flexibility transformation of thermal power units, the importance of risks described by each secondary index is different, so it needs to give different weights. In addition, since the evaluation is focused on the planning period for the flexibility transformation of thermal power units, it is very difficult to obtain the data of the flexibility transformation of the coal-fired thermal power units. According to the proposed generalised framework for selecting the MCDA method [21], the study for the decision-making is including both the qualitative evaluation problems and the quantitative evaluation problems in practice, so it suitable for the TOPSIS evaluation method to deal with the quantitative evaluation part and subjective evaluation method to cope with the qualitative evaluation part. Therefore, this paper selects the expert selection set-valued iterative method which can fully absorb expert opinions to subjectively weight most of the qualitative indexes in the evaluation index system. For a few quantitative indexes, the value can be estimated by the relevant values of the flexibility transformation modified thermal power units, and it is easily seen that the obvious superior and inferior values of the quantitative indexes of the coal-fired flexibility transformation, and the GRA-TOPSIS method is selected and improved combined with grey relation analysis to obtain the final scores of the risk of the decision-making for coal-fired thermal power units flexibility transformation. Additionally, the frame of the proposed hybrid evaluation operation process of the improved TOPSIS based on Grey Relational Analysis (GRA-TOPSIS) is in Figure 1: 


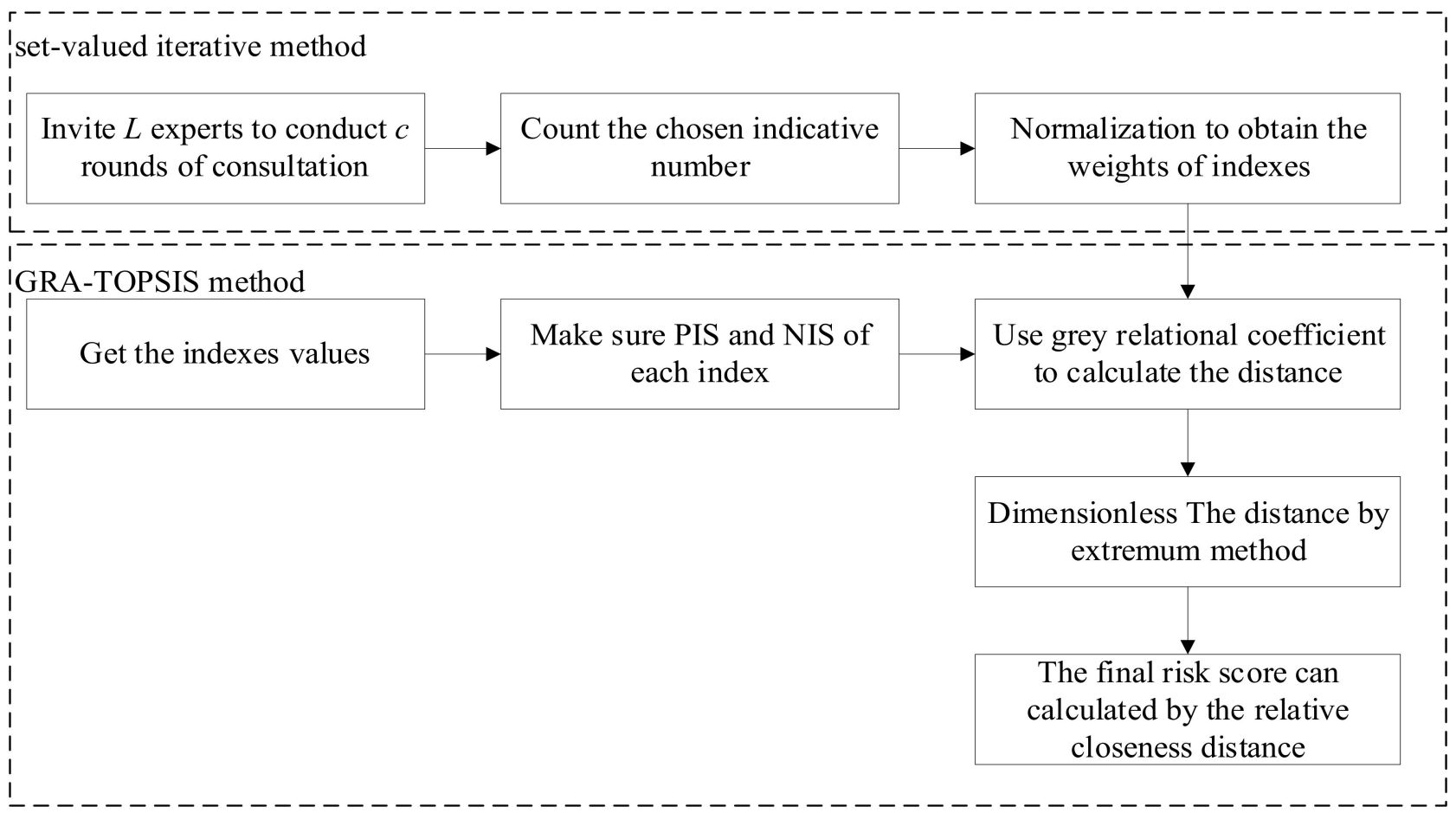

Figure 1. The frame of the hybrid evaluation method of set-valued iterative method and the GRA-TOPSIS method.

\subsection{Subjective Weighting Method Based on the Set-Valued Iteration of Expert Selection}

In the process of subjective weighting, this paper adopts an improved set-value iteration method for subjective weighting, fully absorbing expert opinions, and determining the index weight $\Omega=\left\{\omega_{1}, \omega_{2}, \ldots, \omega_{n}\right\}$. Considering the large number of indexes for the transformation of thermal power units, it is easy to show the inconsistency of weight judgment and thinking of the expert's decision process, this paper has made some improvements to the set-value iteration method of experts. Denote the index set as $E=\left\{e_{1}, e_{2}, \ldots, e_{n}\right\}$ and the steps of the subjective weighting method based on improved set-value iteration are as follows:

1. Invite $L$ experts to conduct $c$ rounds of consultation. In each round of consultation, each expert is required to select the most important $s_{i}(i=1,2, \ldots, c)$ indexes from the index set $E$, and $s_{i}$ is increased round by round. The result selected by the $k$-th expert in the $i$-th round of consultation is $E(i, k)=\left\{e_{1}(i, k), e_{2}(i, k), \ldots, e_{i}(i, k)\right\}$. Obviously, $E(i, k)$ is a subset of $E$.

2. The indicative function is shown in Equation (5):

$$
\mu_{i, k}\left(e_{j}\right)=\left\{\begin{array}{l}
1, e_{j} \in E(i, k) \\
0, e_{j} \notin E(i, k)
\end{array}\right.
$$

where $j=1,2, \ldots, n$.

3. Count the chosen indicative number $g\left(e_{j}\right)$ as Equation (6)

$$
g\left(e_{j}\right)=\sum_{k=1}^{L} \sum_{i=1}^{c}\left(u_{i k}\left(e_{j}\right)+\alpha\right)
$$

where $\alpha>0$ is the adjustment parameter. Considering the large number of indexes, some indexes may not be selected all the time, $\alpha$ can adjust the weight difference between indexes to avoid the indexes weight being too large or too small. According to the indicative function, $\alpha$ can be any real number near 1 . 
After normalization $g\left(e_{j}\right)$, the weigh $e_{j}$ is obtained as Equation (7):

$$
\omega_{j}=g\left(e_{j}\right) / \sum_{j=1}^{n} g\left(e_{j}\right)
$$

\subsection{Objective Weighting Method Based on GRA-TOPSIS}

In the decision-making evaluation index system, due to the large number of indexes, the purpose of the evaluation is to give suggestions on whether it is necessary to carry out flexibility transformation of the coal-fired unit based on the risk level. The target ideal effect after the transformation of the unit can be referred to as the design evaluation of the transformation plan, and the worst effect can also be referred to as the current state. Based on the above reasons, this paper chooses to use the TOPSIS method for comprehensive evaluation. The core of using the TOPSIS method is the positive ideal solution (PIS) and the negative ideal solution (NIS). The above two effects can be understood as PIS and NIS of the flexibility transformation. According to PIS and NIS, The TOPSIS method can sort the plans by calculating the distance between the PIS and NIS. The closer to PIS and farther away from NIS, the better the plan is.

The key of the TOPSIS method is to design a reasonable distance calculation formula. The most common method is to use Euclidean distance [22]. Euclidean distance has the advantages of simple calculation, easy understanding, and good application effect, but it is prone to problems such as preference reversal. In addition, the purpose of the flexibility transformation evaluation of the coal-fired power units is not to require that the plans be evenly distributed between PIS and NIS, and to reflect better sequencing characteristics as much as possible. Rather, it is hoped that each plan has a clear trend towards PIS or NIS, to get a conclusion on whether to carry out flexibility transformation of the coal-fired unit. Therefore, this paper designs an improved TOPSIS method based on Grey Relational Analysis (GRA) [23-26]. The grey relational coefficient can reflect the changing trend of the index sequence, to get the evaluation result of the distance from the overall point of view of the system.

Based on the above analysis, the operation process of the improved TOPSIS based on Grey Relational Analysis (GRA-TOPSIS) is as follows:

1. Suppose the flexibility transformation plan of the coal-fired unit set is $P=\left\{p_{1}, p_{2}, \ldots, p_{m}\right\}$, and the index set is $E=\left\{e_{1}, e_{2}, \ldots, e_{n}\right\}$, and the original evaluation result of plan $p_{i}$ on the index $I_{j}$ is $y_{i j}$, then the original evaluation matrix is $Y=\left(y_{i j}\right)_{m \times n}$.

2. The cost indexes (the higher the evaluation value, the better the peak shaving effect, and the lower the risk level) are first normalized according to Equation (2), and then all indexes are standardized according to Equation (3), then the standardized evaluation matrix $X=\left(x_{i j}\right)_{m \times n}$ is obtained.

3. The positive ideal solution PIS and the negative ideal solution NIS are determined as Equation (8)

$$
P I S=\left\{\max _{i} x_{i j}\right\}=\left\{x_{1}^{+}, x_{2}^{+}, \ldots, x_{n}^{+}\right\}, N I S=\left\{\min _{i} x_{i j}\right\}=\left\{x_{1}^{-}, x_{2}^{-}, \ldots, x_{n}^{-}\right\}
$$

4. Based on the Euclidean distance definition, the distance between each plan and the positive and negative ideal solution is calculated. For the plan $p_{i}$, the distance from the positive ideal solution PIS is $d_{i}^{+}$, and the distance from the negative ideal solution NIS is $d_{i}^{-}$, as Equation (9)

$$
d_{i}^{+}=\sqrt{\sum_{j=1}^{n} \omega_{j}\left(x_{i j}-x_{j}^{+}\right)^{2}}, d_{i}^{-}=\sqrt{\sum_{j=1}^{n} \omega_{j}\left(x_{i j}-x_{j}^{-}\right)^{2}}
$$


where $w_{j}$ is the weight of the index $e_{j}$, is determined by the expert subjective setvalued iterative method mentioned above.

5. Based on the grey relational coefficient, the distance between each plan and the positive and negative ideal solution can be calculated. For the evaluation result $x_{i j}$ of plan $p_{i}$ on index $e_{j}$, the grey relational coefficient with the positive ideal solution PIS is $\gamma_{i j}^{+}$, and the grey relational coefficient with the negative ideal solution NIS is $\gamma_{i j}^{-}$, which is as Equation (10)

$$
\begin{aligned}
& \gamma_{i j}^{+}=\frac{\min _{i} \min _{j}\left|x_{j}^{+}-x_{i j}\right|+\rho \max _{i} \max _{j}\left|x_{j}^{+}-x_{i j}\right|}{\left|x_{j}^{+}-x_{i j}\right|+\rho \max _{i} \max _{j}\left|x_{j}^{+}-x_{i j}\right|} \\
& \gamma_{i j}^{-}=\frac{\min _{i} \min _{j}\left|x_{i j}-x_{j}^{-}\right|+\rho \max _{i} \max _{j}\left|x_{i j}-x_{j}^{-}\right|}{\left|x_{i j}-x_{j}^{-}\right|+\rho \max _{i} \max _{j}\left|x_{i j}-x_{j}^{-}\right|}
\end{aligned}
$$

where $\rho \in[0,1]$ is the resolution coefficient, usually taken as 0.5 . The grey relational coefficient can represent the difference between the plan to be evaluated and PIS or NIS on the curve geometry. In this paper, the reciprocal of the grey correlation coefficient is used to describe the distance. For the plan $p_{i}$, the distance from the positive ideal solution PIS is $r_{i}^{+}$, and the distance from the negative ideal solution NIS is $r_{i}^{-}$, which is as Equation (11)

$$
r_{i}^{+}=\sum_{j=1}^{n} \frac{\omega_{j}}{\gamma_{i j}^{+}}, r_{i}^{-}=\sum_{j=1}^{n} \frac{\omega_{j}}{\gamma_{i j}^{-}}
$$

6. The distance is dimensionless by extremum method, as in Equation (12)

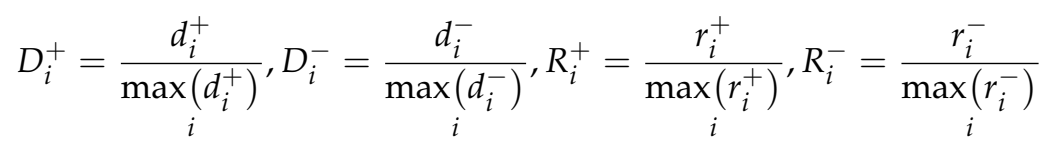

7. The distance calculated by the above two methods is weighted and integrated to obtain the final weighted distance with Equation (13)

$$
W_{i}^{+}=\alpha D_{i}^{+}+(1-\alpha) R_{i}^{+}, W_{i}^{-}=\alpha D_{i}^{-}+(1-\alpha) R_{i}^{-}
$$

where $\alpha \in[0,1]$ is the weighting coefficient, which reflects the preference of the decision maker for the two distances.

8. The relative closeness is calculated based on the weighted distance. According to the practical meaning of PIS and NIS in this article, the calculation formula of relative closeness is as Equation (14),

$$
N_{i}=\frac{W_{i}^{-}}{W_{i}^{+}+W_{i}^{-}}
$$

Based on the relative closeness, the risk of coal-fired units flexibility transformation during the planning period under deep peak shaving demand can be comprehensively evaluated. The greater the relative closeness means the higher risk.

\section{Case Study}

Based on the index system and the hybrid evaluation method designed in this paper, 11 representative coal-fired thermal power units in 10 thermal power plants in Liaoning, Jilin, and Shaanxi provinces in China were selected for the case study on flexibility transformation decision-making. The single capacity of the unit is between 220-350 MW, and it has been put into operation for more than 10 years, which meets the requirements of deep peak shaving flexibility transformation. In addition to the statistical data provided by 
the power plants, five experts from the power plants and five experts related to the power system were invited to evaluate and score by questionnaire.

\subsection{Determination of Index Weight}

Based on the subjective weighting method of improved set-value iteration, the index weights were determined. 10 experts were consulted for three rounds. In addition, each round of consultation required the experts to select the most important three, six, and nine indexes. The adjustment parameter $\alpha$ is set to 1 , and the calculation results of index weight before and after adjustment are shown in Table 2.

Table 2. Calculation results of the index weight.

\begin{tabular}{|c|c|c|c|c|c|c|c|c|c|c|c|c|c|c|c|c|c|}
\hline \multicolumn{2}{|c|}{ Index } & \multirow{3}{*}{$\begin{array}{c}\text { R1 } \\
27 \\
0.150\end{array}$} & \multirow{3}{*}{$\begin{array}{c}\text { R2 } \\
14 \\
0.078\end{array}$} & \multirow{3}{*}{$\begin{array}{c}\text { R3 } \\
13 \\
0.072\end{array}$} & \multirow{3}{*}{$\begin{array}{c}\mathbf{R} 4 \\
0 \\
0.000\end{array}$} & \multirow{3}{*}{$\begin{array}{c}\text { R5 } \\
3 \\
0.017\end{array}$} & \multirow{3}{*}{$\begin{array}{c}\text { R6 } \\
14 \\
0.078\end{array}$} & \multirow{3}{*}{$\begin{array}{c}\text { R7 } \\
13 \\
0.072\end{array}$} & \multirow{3}{*}{$\begin{array}{c}\text { R8 } \\
9 \\
0.050\end{array}$} & \multirow{3}{*}{$\begin{array}{c}\text { R9 } \\
2 \\
0.011\end{array}$} & \multirow{3}{*}{$\begin{array}{c}\text { R10 } \\
1 \\
0.006\end{array}$} & \multirow{3}{*}{$\begin{array}{c}\text { R11 } \\
1 \\
0.006\end{array}$} & \multirow{3}{*}{$\begin{array}{c}\text { R12 } \\
\begin{array}{c}4 \\
0.022\end{array}\end{array}$} & \multirow{3}{*}{$\begin{array}{c}\text { R13 } \\
30 \\
0.167\end{array}$} & \multirow{3}{*}{$\begin{array}{c}\text { R14 } \\
3 \\
0.017\end{array}$} & \multirow{3}{*}{$\begin{array}{c}\text { R15 } \\
26 \\
0.144\end{array}$} & \multirow{3}{*}{$\begin{array}{c}\text { R16 } \\
20 \\
0.111\end{array}$} \\
\hline & $\mathrm{g}$ & & & & & & & & & & & & & & & & \\
\hline Before & $\omega$ & & & & & & & & & & & & & & & & \\
\hline \multirow{2}{*}{ After } & $\mathrm{g}$ & 37 & 24 & 23 & 10 & 13 & 24 & 23 & 19 & 12 & 11 & 11 & 14 & 40 & 13 & 36 & 30 \\
\hline & $\omega$ & 0.109 & 0.071 & 0.068 & 0.029 & 0.038 & 0.071 & 0.068 & 0.056 & 0.035 & 0.032 & 0.032 & 0.041 & 0.118 & 0.038 & 0.106 & 0.088 \\
\hline
\end{tabular}

It can be seen from Table 2:

1. Experts generally believe that indexes R1, R13, and R15 are more important. Among them, the index R13 'peak shaving margin risk' is selected by each expert in each round of consultation.

2. The index R4 "burner characteristics" has not been selected. By adjusting the parameter $\alpha$, the weight of $\mathrm{R} 4$ can be avoided to be 0 and the weight difference between the indexes can be reduced.

3. The adjusted weight is taken as the final index weight. From the weight distribution, the operational risks of thermal power units under deep peak shaving demand are mainly concentrated on the peak shaving effect and the boiler side.

\subsection{Hybrid Comprehensive Evaluation and Analysis}

A total of 11 thermal power units (denoted as $P_{i}, i=1,2, \ldots, 11$ ) are evaluated comprehensively in the planning period. Firstly, the initial evaluation data are obtained according to the index system: (1) For the five quantitative indexes, the evaluation values are directly calculated based on the statistical data provided by each power plant; (2) For 11 qualitative indexes, experts are invited to use a five-level scale $\{1=$ very low, $2=$ low, $3=$ medium, $4=$ high, $5=$ very high $\}$ for evaluation and scoring, and the evaluation results of 10 experts are equal integrated, and the raw data of the indexes of 11 thermal power plants are shown in Table 3.

Table 3. The raw data of the indexes of 11 thermal power plants.

\begin{tabular}{|c|c|c|c|c|c|c|c|c|c|c|c|c|c|c|c|c|}
\hline Units $\quad$ Index & R1 & R2 & R3 & R4 & R5 & R6 & R7 & R8 & R9 & R10 & R11 & R12 & R13 & R14 & R15 & R16 \\
\hline P1 & 30 & 3 & 2 & 4.1 & 3 & 2.1 & 9 & 3 & 4 & 5.5 & 2 & 3.9 & 6 & 3 & 6 & 4.5 \\
\hline P2 & 40 & 1 & 6 & 3.6 & 5 & 4.1 & 7 & 5.7 & 2.5 & 3.1 & 3.3 & 2.2 & 8 & 5 & 2.1 & 2.4 \\
\hline P3 & 40 & 0 & 4.2 & 4.5 & 6 & 5.5 & 7 & 5.1 & 2.8 & 2.9 & 4.9 & 2.1 & 8 & 5.6 & 2.4 & 3.2 \\
\hline $\mathrm{P} 4$ & 50 & 1 & 2.4 & 3.7 & 6 & 2.2 & 8 & 2.1 & 5 & 3.5 & 5.1 & 3.2 & 7 & 4.8 & 3.9 & 4 \\
\hline P5 & 50 & 5 & 5.5 & 2.2 & 6 & 5.5 & 8 & 3.7 & 4.4 & 5.9 & 4.8 & 4.7 & 3 & 5.6 & 5 & 5.3 \\
\hline P6 & 50 & 5 & 4.5 & 5.7 & 7 & 5.1 & 6 & 5.7 & 5.8 & 5.5 & 5.3 & 7 & 5 & 4.2 & 7 & 4.5 \\
\hline P7 & 50 & 6 & 5.9 & 4.6 & 7 & 4.5 & 5 & 4.9 & 4.8 & 5.4 & 4.1 & 4.2 & 2 & 4.1 & 9 & 4.4 \\
\hline P8 & 60 & 2 & 7.6 & 6.4 & 7 & 7.2 & 7 & 4.2 & 5.2 & 7.5 & 4.3 & 4.9 & 3 & 5.3 & 3.9 & 5.3 \\
\hline P9 & 60 & 4 & 6.2 & 5.8 & 7 & 2.6 & 6 & 7.2 & 7.8 & 4.4 & 7 & 4.4 & 5 & 6.3 & 5.4 & 3.5 \\
\hline P10 & 60 & 4 & 5.3 & 7.2 & 8 & 4.2 & 5 & 6 & 7.4 & 7.3 & 6.1 & 5.7 & 6 & 4.5 & 5.2 & 6.4 \\
\hline P11 & 60 & 7 & 6.5 & 7.6 & 8 & 6.7 & 4 & 4 & 7 & 6.2 & 7.5 & 2.7 & 4 & 4.5 & 6.8 & 5.6 \\
\hline
\end{tabular}


The evaluation matrix $X$ after normalization and standardization according to formulas (2) and (3) is shown in Table 4.

Table 4. Evaluation matrix after normalization.

\begin{tabular}{|c|c|c|c|c|c|c|c|c|c|c|c|c|c|c|c|c|}
\hline Units Index & R1 & $\mathbf{R} 2$ & R3 & R4 & R5 & R6 & R7 & R8 & R9 & R10 & R11 & R12 & R13 & R14 & R15 & R16 \\
\hline P1 & -2.10 & -0.21 & -1.90 & -0.59 & -2.46 & -1.48 & 1.71 & -1.21 & -0.69 & 0.20 & -1.96 & -0.13 & 0.42 & -2.11 & 0.43 & 0.03 \\
\hline P2 & -1.05 & -1.14 & 0.55 & -0.91 & -1.00 & -0.26 & 0.32 & 0.72 & -1.59 & -1.40 & -1.10 & -1.32 & 1.45 & 0.22 & -1.57 & -1.87 \\
\hline P3 & -1.05 & -1.61 & -0.55 & -0.34 & -0.27 & 0.60 & 0.32 & 0.29 & -1.41 & -1.54 & -0.03 & -1.39 & 1.45 & 0.92 & -1.41 & -1.14 \\
\hline P4 & 0.00 & -1.14 & -1.66 & -0.85 & -0.27 & -1.42 & 1.01 & -1.85 & -0.09 & -1.14 & 0.10 & -0.62 & 0.93 & -0.01 & -0.64 & -0.42 \\
\hline P5 & 0.00 & 0.72 & 0.25 & -1.80 & -0.27 & 0.60 & 1.01 & -0.71 & -0.45 & 0.47 & -0.10 & 0.43 & -1.12 & 0.92 & -0.08 & 0.76 \\
\hline P6 & 0.00 & 0.72 & -0.37 & 0.42 & 0.47 & 0.36 & -0.38 & 0.72 & 0.39 & 0.20 & 0.24 & 2.03 & -0.09 & -0.71 & 0.95 & 0.03 \\
\hline P7 & 0.00 & 1.19 & 0.49 & -0.28 & 0.47 & -0.01 & -1.08 & 0.15 & -0.21 & 0.13 & -0.56 & 0.08 & -1.64 & -0.83 & 1.97 & -0.06 \\
\hline P8 & 1.05 & -0.68 & 1.54 & 0.86 & 0.47 & 1.64 & 0.32 & -0.35 & 0.03 & 1.54 & -0.43 & 0.57 & -1.12 & 0.57 & -0.64 & 0.76 \\
\hline P9 & 1.05 & 0.25 & 0.68 & 0.48 & 0.47 & -1.17 & -0.38 & 1.79 & 1.59 & -0.53 & 1.37 & 0.22 & -0.09 & 1.74 & 0.13 & -0.87 \\
\hline P10 & 1.05 & 0.25 & 0.12 & 1.37 & 1.20 & -0.19 & -1.08 & 0.94 & 1.35 & 1.40 & 0.77 & 1.13 & 0.42 & -0.36 & 0.02 & 1.75 \\
\hline P11 & 1.05 & 1.65 & 0.86 & 1.62 & 1.20 & 1.33 & -1.77 & -0.49 & 1.11 & 0.67 & 1.70 & -0.97 & -0.61 & -0.36 & 0.84 & 1.03 \\
\hline
\end{tabular}

The calculation is solved step by step according to the hybrid comprehensive evaluation method based on GRA-TOPSIS designed in Section 3.2. The weighting coefficient $\alpha$ is 0.4. Based on Euclidean distance, grey relational coefficient and weighted integration, the dimensionless distance and relative closeness of 11 units are calculated as shown in Table 5, and the relative closeness of weighted integration is used as the final evaluation result.

Table 5. Calculation results of closeness.

\begin{tabular}{|c|c|c|c|c|c|c|c|c|c|c|}
\hline Units & $D^{+}$ & $D^{-}$ & $R^{+}$ & $R^{-}$ & $N_{D}$ & $\begin{array}{l}\text { Sorting } \\
\text { Based on } \\
\text { TOPSIS }\end{array}$ & $N_{R}$ & $\begin{array}{c}\text { Sorting } \\
\text { Based on } \\
\text { GRA-TOPSIS }\end{array}$ & $N$ & $\begin{array}{c}\text { Comprehensive } \\
\text { Sorting }\end{array}$ \\
\hline P1 & 2.457 & 1.568 & 1.466 & 1.268 & 0.384 & 1 & 0.460 & 1 & 0.432 & 1 \\
\hline P2 & 2.415 & 1.667 & 1.450 & 1.286 & 0.403 & 2 & 0.467 & 2 & 0.443 & 2 \\
\hline P3 & 2.287 & 1.729 & 1.430 & 1.308 & 0.425 & 4 & 0.474 & 3 & 0.456 & 4 \\
\hline $\mathrm{P} 4$ & 2.248 & 1.644 & 1.433 & 1.305 & 0.417 & 3 & 0.474 & 3 & 0.453 & 3 \\
\hline P5 & 1.705 & 1.978 & 1.344 & 1.396 & 0.532 & 6 & 0.506 & 6 & 0.515 & 6 \\
\hline P6 & 1.423 & 2.109 & 1.301 & 1.437 & 0.592 & 9 & 0.522 & 7 & 0.545 & 9 \\
\hline P7 & 1.834 & 2.053 & 1.350 & 1.391 & 0.523 & 5 & 0.504 & 5 & 0.511 & 5 \\
\hline P8 & 1.666 & 2.284 & 1.300 & 1.438 & 0.573 & 7 & 0.522 & 7 & 0.541 & 7 \\
\hline P9 & 1.622 & 2.285 & 1.299 & 1.439 & 0.580 & 8 & 0.522 & 7 & 0.543 & 8 \\
\hline P10 & 1.357 & 2.471 & 1.245 & 1.486 & 0.640 & 11 & 0.541 & 11 & 0.576 & 11 \\
\hline P11 & 1.550 & 2.512 & 1.255 & 1.477 & 0.613 & 10 & 0.537 & 10 & 0.565 & 10 \\
\hline
\end{tabular}

It can be seen from Table 4 that:

1. The sorting results of the eleven units by the basic TOPSIS evaluation method are based on the Euclidean distance between PIS and NIS, and if the units near the PIS and far from the NIS, the sorting number is smaller. According to sorting results of the GRA-TOPSIS based on the grey relational coefficient, P3, P4 and P6, P8, P9 are the same sorting number, the results are different from the basic TOPSIS method, but the others sorting the number of other units are the same as basic TOPSIS method. The proposed evaluation method is combined the expert's option, and the sorting results are consistent with the basic TOPSIS method.

2. Calculating the closeness based on the Euclidean distance as the TOPSIS method, there is no situation where the scores of the two plans are equal, which can widen the gap between the plans. However, calculating the closeness based on the grey relational coefficient, the results of two or three plans are equal, but the hierarchical relationship between the plans can be reflected more clearly.

3. The proposed method is combining the advantages of the two evaluation methods, the relative closeness of weighted integration is taken as the final evaluation result to reflect the rationality of the methods. The decision-making evaluation results for flexibility transformation of the thermal power unit are shown in Figure 2. 


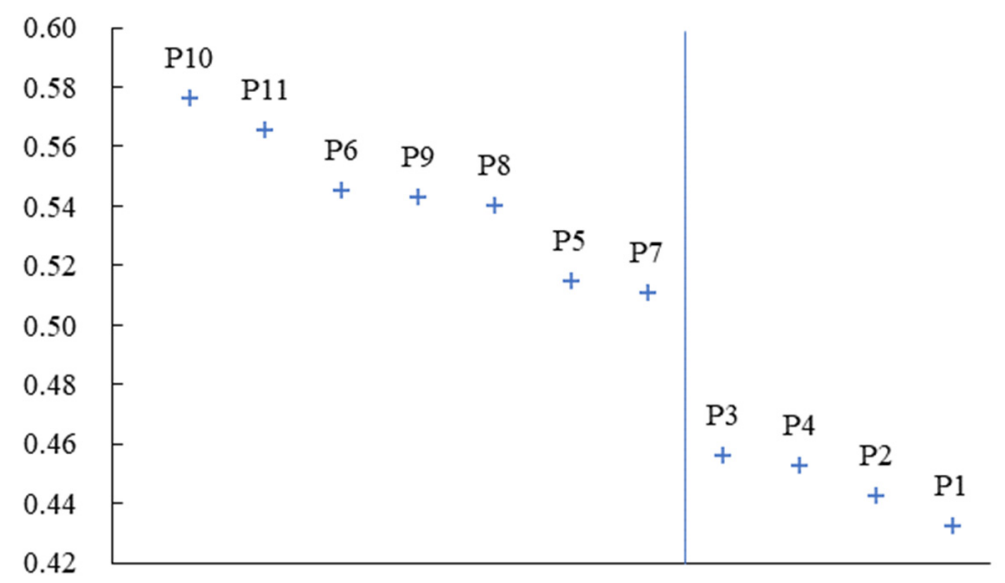

Figure 2. Decision-making evaluation results for flexibility transformation of thermal power unit under deep peak shaving demand.

It can be seen from Figure 2 that:

1. The operating risk of 11 units is between 0.42 and 0.6 . With the risk value of 0.5 as a reference point, the risk of the unit in the planning period can be divided into high and low levels.

2. Units with lower risk levels include P1, P2, P3, and P4.

3. Further analysis is made on the units with higher risk level:

a. The risk level of units P10 and P11 is relatively high. It can be seen from Table 2 that the risks of the unit P10 are mainly concentrated in the indexes R8, R9, $\mathrm{R} 10, \mathrm{R} 12$, which indicates that the operating conditions of the steam turbine are poor during the deep peak shaving. Therefore, attention should be paid to the renovation and upgrading of the steam turbine when designing the flexibility transformation plan of "one machine, one policy".

b. The risk of unit P11 is relatively dispersed, and the indexes are generally weak.

c. The risk levels of units P6, P8, and P9 are similar, and the index evaluation values are also similar, representing the general level of the unit.

d. The risk level of the units P5 and P7 is relatively low, and better results can be achieved by improving the weak indexes in a targeted manner during flexibility transformation. For example, it is only necessary to focus on reducing the excessive emission of unit P5 and optimizing its control system, improving the coal quality and the peak shaving strategy of unit P7.

\section{Conclusions}

The empirical research verifies the feasibility of the evaluation index system and evaluation method proposed in this paper. Based on the empirical research, the main conclusions are as follows:

1. The flexibility transformation decision-making evaluation index system for coal-fired power units under deep peak shaving in the planning period designed in this paper takes into account the general evaluation indexes of thermal power unit operation risks and the characteristics of low-load operation of thermal power units, which reflects the scientific and specificity and has reference value for relevant evaluation.

2. According to the index system designed in this paper, the adjustment parameter $\alpha$ is introduced on the basis of the set-valued iteration method, multiple rounds of expert consultation are implemented, and a subjective weighting method based on improved set-valued iteration is designed. Integrating the grey relational coefficient and Euclidean distance weighting and combining the advantages of the two methods, a comprehensive evaluation method based on GRA-TOPSIS is designed. This method 
is suitable for giving suggestions on whether it is necessary to carry out flexibility transformation based on the evaluation results.

3. An empirical analysis of 11 coal-fired units in China that meet the requirements of deep peak shaving flexibility transformation was conducted, and the validity, reliability, and rationality of the index system and evaluation method were verified.

The evaluation results show that:

a. Experts generally believe that "peak shaving margin risk" is more important, while "burner characteristics" is relatively unimportant.

b. Peak shaving risks are mainly concentrated on the peak shaving effect and the boiler side.

c. The operating risks of 11 units are clearly divided into high and low levels.

d. Units with lower risk levels include P1, P2, P3, and P4, it is not recommended to carry out flexibility transformation for these units immediately.

e. Units with higher risk level can be further analyzed and based on the evaluation results, the targeted "one machine, one policy" flexibility transformation suggestion is given.

Although the study focused on the decision-making of the flexibility transformation decision-making of coal-fired units and give the evaluation results of the 11 coal-fired units in the case study, we also think that it has great potential in the application of evaluation to other types of the coal-fired units flexibility transformation decision-making. Because it is difficult to collect the monitoring and statistical data of each power plant comprehensively and accurately, the evaluation and scoring of most indexes rely on the subjective opinions of experts, which reduces the objectivity of the evaluation in this paper to a certain extent. In addition, the units selected in the empirical research have certain limitations. If more typical units are selected from the whole country (larger capacity, higher parameters, stronger peak shaving demand), whether the index weight design is still reasonable and other issues need to be further studied. Thus, we hope that our paper serves as a starting point and encourages fellow researchers to adapt or reference our method to their respective fields of application.

Author Contributions: J.W. conceived and designed the study, L.L. completed the papers in English and gave much good research advice. J.H. realize the evaluation algorithm with Matlab, S.Z. collected the data, Y.T. analyzed the data, T.H. checked the whole paper and provide the raw data materials. All authors have read and agreed to the published version of the manuscript.

Funding: This research was funded by National Natural Science Foundation of China, grant number 72071077, Beijing Social Science Foundation, grant number 19GLB024,18GLB025, Qin Xin Talents Cultivation Program of Beijing Information Science \& Technology University, grant number QXTCPB201703 and the Fundamental Research Funds for the Central Universities, grant number 2020FR001.

Institutional Review Board Statement: Not applicable.

Informed Consent Statement: Not applicable.

Data Availability Statement: All data is contained within the article.

Conflicts of Interest: The authors declare no conflict of interest.

Abbreviations
$\begin{array}{llll}\text { Nomenclature } & & \\ \text { Symbols } & & \\ \text { BMCR } & \text { boiler maximum continuous rating } & \text { R } & \text { Index symbol } \\ \text { BMLR } & \text { Boiler minimum combustion stable load rate } & \text { P } & \text { flexibility transformation plan of the coal-fired unit } \\ \text { E } & \text { Index set } & \text { Y } & \text { the original evaluation matrix } \\ \omega & \text { Weight value } & \text { PIS } & \text { positive ideal solution }\end{array}$




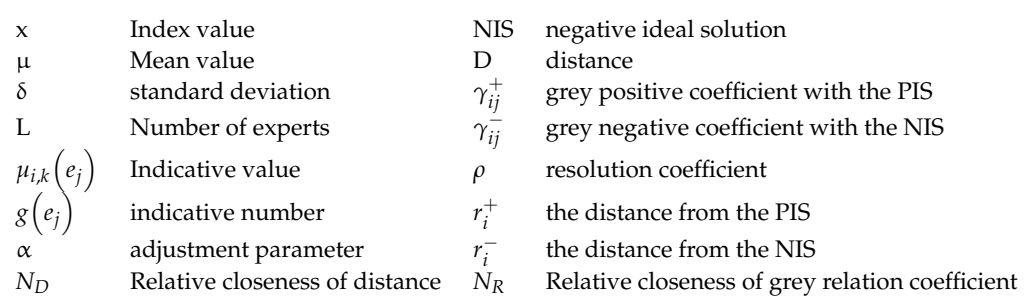

\section{References}

1. Moseev, G.I.; Rubin, V.B. The scientific and technical problems of increasing the flexibility of thermal power stations. Therm. Eng. 1982, 29, 295-296.

2. Brauner, G.; Bofinger, S.; Glaunsinger, W.; Pyc, I.; Steinke, F.; Schwing, U.; Magin, W. Flexibility of thermal power generation for RES supply in Germany until 2020. eEi Elektrotechnik und Inf. 2014, 131, 361-365.

3. Kubik, M.L.; Coker, P.; Barlow, J. Increasing thermal plant flexibility in a high renewables power system. Appl. Energy 2015, 154, 102-111. [CrossRef]

4. Richter, M.; Oeljeklaus, G.; Görner, K. Improving the load flexibility of coal-fired power plants by the integration of a thermal energy storage. Appl. Energy 2019, 236, 607-621. [CrossRef]

5. Nuytten, T.; Claessens, B.; Paredis, K.; Van Bael, J.; Six, D. Flexibility of a combined heat and power system with thermal energy storage for district heating. Appl. Energy 2013, 104, 583-591. [CrossRef]

6. Cao, R.; Lu, Y.; Yu, D.; Guo, Y.; Bao, W.; Zhang, Z.; Yang, C. A novel approach to improving load flexibility of coal-fired power plant by integrating high temperature thermal energy storage through additional thermodynamic cycle. Appl. Therm. Eng. 2020, 173, 115225. [CrossRef]

7. Finck, C.; Li, R.; Kramer, R.; Zeiler, W. Quantifying demand flexibility of power-to-heat and thermal energy storage in the control of building heating systems. Appl. Energy 2018, 209, 409-425. [CrossRef]

8. Garbrecht, O.; Bieber, M.; Kneer, R. Increasing fossil power plant flexibility by integrating molten-salt thermal storage. Energy 2017, 118, 876-883. [CrossRef]

9. Luo, G.; Zhang, X.; Liu, S.; Dan, E.; Guo, Y. Demand for flexibility improvement of thermal power units and accommodation of wind power under the situation of high-proportion renewable integration-taking North Hebei as an example. Environ. Sci. Pollut. Res. 2019, 26, 7033-7047. [CrossRef]

10. Brouwer, A.S.; van den Broek, M.; Seebregts, A.; Faaij, A. Operational flexibility and economics of power plants in future low-carbon power systems. Appl. Energy 2015, 156, 107-128. [CrossRef]

11. Liu, J.; Guo, T.; Wang, Y.; Li, Y.; Xu, S. Multi-Technical Flexibility Retrofit Planning of Thermal Power Units Considering High Penetration Variable Renewable Energy: The Case of China. Sustainability 2020, 12, 3543. [CrossRef]

12. Ye, X.; Wang, C.; Li, Q.; Shi, Z.; Liu, X.; Liu, Y. Research on Optimal Operation Strategy with Ancillary Services of Flexible Thermal Power Units. In Proceedings of the 2018 Chinese Automation Congress (CAC), Xi'an, China, 30 November-2 December 2018; pp. 2990-2995. [CrossRef]

13. Gang, L. Analysis on technical route of flexible transformation of thermal power units. Power Syst. Eng. 2018, 34, 12-15.

14. Avagianos, I.; Violidakis, I.; Karampinis, E.; Rakopoulos, D.; Nanos, E.; Polonidis, N.; Papapavlou, C.; Grammelis, P.; Kakaras, E. Thermal Simulation and Economic Study of Predried Lignite Production Retrofit of a Greek Power Plant for Enhanced Flexibility. J. Energy Eng. 2019, 145, 04019001. [CrossRef]

15. Ye, L.-C.; Lin, H.X.; Tukker, A. Future scenarios of variable renewable energies and flexibility requirements for thermal power plants in China. Energy 2019, 167, 708-714. [CrossRef]

16. Guo, T.; Gao, Y.; Zhou, X.; Li, Y.; Liu, J. Optimal scheduling of power system incorporating the flexibility of thermal units. Energies 2018, 11, 2195. [CrossRef]

17. China 2050 High Renewable Energy Penetration Scenario and Roadmap Study. Available online: https://www.efchina.org/ Reports-en/china-2050-high-renewable-energy-penetration-scenario-and-roadmap-study-en (accessed on 20 April 2015).

18. Zhao, Y.; Liu, M.; Wang, C.; Li, X.; Chong, D.; Yan, J. Increasing operational flexibility of supercritical coal-fired power plants by regulating thermal system configuration during transient processes. Appl. Energy 2018, 228, 2375-2386. [CrossRef]

19. Qi, M.; Luo, H.; Wei, P.; Fu, Z. Estimation of low calorific value of blended coals based on support vector regression and sensitivity analysis in coal-fired power plants. Fuel 2019, 236, 1400-1407. [CrossRef]

20. Gu, Y.; Xu, J.; Chen, D.; Wang, Z.; Li, Q. Overall review of peak shaving for coal-fired power units in China. Renew. Sustain. Energy Rev. 2016, 54, 723-731. [CrossRef]

21. Wątróbski, J.; Jarosław, J.; Ziemba, P.; Karczmarczyk, A.; Zioło, M. Generalised framework for multi-criteria method selection. Omega 2019, 86, 107-124. [CrossRef]

22. Deng, H.; Yeh, C.H.; Willis, R.J. Inter-company comparison using modified TOPSIS with objective weights. Comput. Oper. Res. 2000, 27, 963-973. [CrossRef]

23. Arslan, T. A weighted wuclidean distance based TOPSIS method for modeling public subjective judgments. Asia-Pac. J. Oper. Res. 2017, 34, 1750004. [CrossRef] 
24. Hu, Y.; Wu, L.; Shi, C.; Wang, Y.; Zhu, F. Research on optimal decision-making of cloud manufacturing service provider based on grey correlation analysis and TOPSIS. Int. J. Prod. Res. 2020, 58, 748-757. [CrossRef]

25. Kirubakaran, B.; Ilangkumaran, M. Selection of optimum maintenance strategy based on FAHP integrated with GRA-TOPSIS. Ann. Oper. Res. 2016, 245, 285-313. [CrossRef]

26. Peng, A.; Wang, Z. GRA-based TOPSIS decision-making approach to supplier selection with interval number. In Proceedings of the 2011 Chinese Control and Decision Conference (CCDC), Mianyang, China, 23-25 May 2011; pp. 1742-1747. 